\title{
KEHANDALAN PELAYANAN KARTU INDONESIA SEHAT DI KELURAHAN KAMELOH BARU KECAMATAN SABANGAU KOTA PALANGKARAYA
}

\author{
Reliability of Indonesia Healthy card service in New Kameloh Sub District of Sabangau \\ in Palangkaraya City
}

\section{Indah Tri Handayani* Siti Alimah}

Universitas Muhammadiyah Palangkaraya, Palangka Raya, Central Kalimantan, Indonesia

email: indahtry.it@gmail.com

\author{
Kata Kunci: \\ Kehandalan \\ Pelayanan \\ Kartu \\ Indonesia Sehat

Keywords:
Reliability
Service
Card
Indonesia Healthy

\section{Accepted}

January 2016

\section{Published}

April 2016

\begin{abstract}
Abstrak
Tujuan dari penelitian ini adalah untuk mengetahui, dan mendiskrifsikan tentang Kehandalan Pelayanan Kartu Indonesia Sehat di Kantor Kelurahan Kameloh Baru Kecamatan Sabangau Kota Palangka Raya. Jenis penelitian yang digunakan dalam penelitian ini adalah deskriftif. Dengan menggunakan metode penelitian kualitatif. Jenis data didalam penelitian ini adalah data primer yang meliputi Pegawai Seksi Kesejahteraan Sosial, Lurah dan Masyarakat Kelurahan Kameloh Baru Kecamatan Sabangau Kota Palangka Raya. Sedangkan data sekundernya berasal dari dokumentasi, sumber data fustaka lainnya, tehnik penggumpulan data menggunakan wawancara, observasi, dan dokumentasi.

Berdasarkan hasil penelitian ini kehandalan pelayanan yang diberikan oleh Seksi Kesejahteraan Sosial di Kelurahan Kameloh Baru Kecamataan Sabangau Kota Palangka Raya, masih belum sesuai dengan harapan masyarkat hal ini dapat dilihat dari Dalam kemampuan dan kehandalan untuk menyediakan pelayanan yang terpercaya pihak kelurahan masih belum mampu bertanggung jawab dalam menyelesaikan tugasnya. Kecermatan atau ketelitian pegawai dalam melayani masyarakat atau pengguna layanan masih belum cermat dan teliti. karena masih banyak keluhan masyarakat atau pelanggan mengenai kurangnya kecermatan dan ketelitian pegawai dalam penulisan nama, dalam mencek berkas-berkas masyarakat serta menyelesaikan berkas-berkas masyarakat.
\end{abstract}

\begin{abstract}
The purpose of this research is to know and to describe the reliability of Indonesia's Healthy card service in the new Office Kameloh Sabangau District of Palangka Raya. The type of research used in this study is deskriftif. Using qualitative research methods. The type of data in this study is primary data that includes social welfare officers, Lurah and the new District Community Kameloh Sabangau Palangka Raya. Secondary data comes from documentation, other data sources, data collection techniques using interviews, observations, and documentation.

Based on the results of the reliability of this research service provided by the Social Welfare section of the new Kameloh village of Sabangau of Palangka Raya, still not in accordance with the expectations of society can be seen from within the ability and Reliability to provide reliable service that the village is still not able to take responsibility in completing its task. The accuracy or thoroughness of staff in serving the community or service users is still not careful and thorough. Because there are still many complaints of people or customers about the lack of accuracy and thoroughness of employees in the writing of names, in examining the community files and resolving community files.
\end{abstract}

\section{PENDAHULUAN}

Kesehatan menjadi salah satu tolok ukur kemajuan bangsa di samping tingkat pendidikan dan perekonomian, sebagaimana tercakup dalam Human Development Index (HDI). Alasan tersebut tidak berlebihan jika kesehatan ditempatkan sebagai salah satu kebutuhan terpenting bagi manusia. Tanpa sehat, manusia mustahil dapat melakukan berbagai kegiatan produktif khususnya dalam pembangunan generasi mendatang yang lebih berkualitas.

Masyarakat kelurahan kameloh baru adalah masyarakat yang menengah kebawah dimana disana masyarakat tinggal dipinggiran sungai yang perekonomiannya sangat kecil, mata pencahariannya hanya nelayan dan 
pedagang. Masyarakat disana sangat membutuhkan Kartu Indonesia Sehat, yang dimana Kartu Indonesia Sehat sangat membantu mereka berobat yang jika mengunakan Kartu Indonesia Sehat ini tidak akan dipunggut biaya, membantu keuangan perekonomian meraka dan membantu kesejahteraan masyarakat secara kesehatan. Kartu Indonesia Sehat berfungsi sebagai kartu jaminan kesehatan, yang dapat digunakan untuk mendapatkan layanan kesehatan secara gratis di fasilitas kesehatan tingkat pertama dan tingkat lanjut sesuai dengan kondisi penyakit yang di derita penerima Kartu Indonesia Sehat.

Kartu Indonesia Sehat adalah program yang dikeluarkan oleh presiden Joko Widodo dan wakil presiden Jusuf Kalla untuk membuat rakyat lebih sehat dan sejahtera. Berselang 14 hari setelah dilantik sebagai Presiden RI ke-7, Joko Widodo resmi meluncurkan KIS bersamaan juga dengan KIP (Kartu Indonesia Pintar) dan KKS (Kartu Keluarga Sejahtera).

Kartu Indonesia Sehat (KIS) sendiri adalah kartu yang memiliki fungsi untuk memberikan jaminan kesehatan kepada masyarakat untuk mendapatkan pelayanan kesehatan secara gratis. Kartu ini sendiri merupakan program yang bertujuan untuk melakukan perluasan dari program kesehatan yang sebelumnya yaitu BPJS Kesehatan yang telah diluncurkan oleh mantan presiden SBY (Susilo Bambang Yudhoyono) pada tanggal I Maret 2014.

Dari observasi yang peneliti dapatkan bahwa masih banyak keluhan dari masyarakat kelurahan kameloh baru kecamatan sabangau Kota Palangka Raya, banyak kesulitan ketika memperoleh pembuatan Kartu Indonesia Sehat (KIS), petugasnya masih banyak yang kurang teliti dalam melayani masyarakat atau pengguna layanan, masih kurang teliti dalam mencek berkasberkas masyarakat, minimnya informasi atau tidak ada kejelasan informasi dalam proses pembuatan kartu indonesia sehat (KIS).
Kualitas terdiri dari segala sesuatu yang bebas dari kekurangan atau kerusakan. Menurut Trilestari (Hardiansyah, 2011:35) berpendapat bahwa pada dasarnya terdapat tiga orientasi kualitas yang seharusnya konsisten antara yang satu dengan yang lain, yaitu persepsi pelanggsan, produk, dan proses. Kualitas pelayanan merupakan suatu kondisi dimana tercipta hubungan yang dinamis antara pengguna maupun pemberi layanan, baik jasa, manusia. Pelayanan publik berkaitan erat dengan kemampuan,daya tanggap, ketepatan waktu, dan sarana prasarana yang tersedia. Zeithaml dkk (Hardiyansyah, 20ll:46-47) kualitas pelayanan dapat diukur dari 5 dimensi, yaitu : Tangible (berwujud), Reability (kehandalan), Responsiviness (ketanggap an), Assurancce (Jaminan), Empaty (Empati).

Adapun Dimensi Reability (Kehandalan), terdiri atas indikator :

a. Kecermatan pegawai dalam melayani pengguna layanan.

b. Memiliki Standar pelayanan yang jelas.

c. Kemampuan menggunakan alat bantu pelayanan.

d. Keahlian petugas menggunakan alat bantu pelayanan.

\section{METODOLOGI}

Peneliti menggunakan metode kualitatif, metode kualitatif adalah suatu penelitian ilmiah yang bertujuan untuk memahami suatu fenomena dalam kontek sosial secara alamiah dengan mengedepankan proses interaksi komunikasi yang mendalam antara penelitian dengan fenomena yang diteliti. Maka penelitian ini mengunakan pendekatan kualitatif karena peneliti ingin mengetahui Kehandalan Pelayanan Kartu Indonesia Sehat di Kelurahan Kameloh Baru Kecamatan Sabangau Kota Palangka Raya. 


\section{HASIL DAN PEMBAHASAN}

Kecermatan atau ketelitian pegawai dalam melayani pengguna layanan sangat penting bagi proses pelayanan. Jika pegawai tidak cermat dalam melayani masyarakat maka akan terjadi kesalahan dan menimbulkan pekerjaan baru. Berdasarkan hasil wawancara peneliti dengan responden ada beberapa warga atau masyarakat yang mendapatkan pelayanan tidak memuaskan. seperti masih banyak pegawai yang kurang teliti dalam menanggani berkas masyarakat atau penguna layanan,kurang teliti dalam penulisan nama diberkas pengguna layanan ketidakjelasan informasi dalam memberikan standar atau prosedur pelayanan dan masih ada pegawai yang belum terlalu mampu mengusai alat bantu dalam proses pelayanan.

Dari ketidakcermatan tersebut akan menimbulkan pekerjaan baru yang seharusnya tidak perlu dilakukan oleh pegawai, serta akan menimbulkan penilaian yang kurang baik oleh pengguna layanan terhadap pelayanan yang diberikan. Maka dari itu pegawai harus cermat dalam mengerjakan tanggung jawab tugas khususnya yang berkaitan dengan pelayanan agar tercipta pelayanan yang baik dan masyarakat akan menilai baik.

Kantor Kelurahan Kameloh Baru sudah memiliki Standar pelayanan yang jelas. Standar ini meliputi prosedur pelayanan, waktu pelayanan, biaya pelayanan, produk pelayanan, sarana prasarana, dan kompetensi petugas pelayanan. Namun masyarakat sebagai pengguna layanan tidak semuanya mengetahui standar pelayanan publik di kantor Kelurahan Kameloh Baru.

Banyak masyarakat mengatakan bahwa pegawai kelurahan kameloh baru kecamatan sabangau kota palangkaraya masih belum memberikan kejelasan dalam prosedur pelayanan, syarat-syarat untuk membuat kartu indonesia sehat, kartu anak pintar dan kartu lainnya.
Kemampuan pegawai menggunakan alat bantu dalam proses pelayanan merupakan modal yang sangat penting dalam menunjang kualitas pelayanan. Namun, berdasarkan hasil wawancara peneliti dengan responden juga banyak masyarakat mengatakan bahwa pegawai dikelurahan kameloh baru ada beberapa yang masih belum terlalu mampu menggunakan alat bantu untuk pelayanan seperti contohnya menggunakan komputer hal tersebut membuat pengguna layanan atau masyarakat menunggu saat proses pelayanan berjalan.

\section{KESIMPULAN}

Berdasarkan hasil penelitian yang telah dilakukan dalam penelitian ini, maka peneliti menyiimpulkan bahwa Kehandalan pelayanan Kartu Indonesia Sehat di Kantor Kelurahan Kameloh Baru Kecamatan Sabangau Kota Palangka Raya masih belum handal dan belum sesuai dengan harapan masyarakat sebagai pengguna jasa dari aparatur pemerintah, baik dalam pelaksanaannya karena dalam kemampuan dan kehandalan untuk menyediakan pelayananyang terpercaya pihak kelurahan kameloh baru kcamatan sabangau kota palangka raya masih belum mampu bertanggung jawab dalam menyelesaikan tugasnya. Kecermatan atau ketelitian pegawai dalam melayani masyarakat atau pengguna layanan masih belum cermat dan teliti. karena masih banyak keluhan masyarakat atau pelanggan mengenai kurangnya kecermatan dan ketelitian pegawai.

Maka diharapkan kepada pegawai kelurahan di Kantor Kelurahan Kameloh Baru Kecamatan Sabangau Kota Palangka Raya harus lebih bertanggung jawab dalam menyelesaikan berkas, harus lebih teliti lagi dalam menulis nama di berkas pengguna layanan. Dan Standar prosedur pelayanan harus jelas agar masyarakat atau pengguna layanan tau jika ingin membuat kartu indonesia sehat pengguna layanan mengetahui syarat- 
syarat untuk pembuatan kartu indonesia sehat,dan seharusnya ada informasi- informasi dimading mengenai syarat-syarat pelayanan.

\section{REFERENSI}

Adya,Atya.2004. Dasar-Dasar Pelayanan Prima. Jakarta:

PT. Elex Media Komputindo.

Barsya, Fitriyanti. 2014. Pelaksanaan Pelayanan Kesehatan Di Puskesmas Pembantu (Pusban) Kecamatan Sangkulirang Kabupaten Kutai Timur. Jurnal Administrasi Negara.Volume 4, Nomor 2, 2014

Djuardi. 2008. Kepuasan Masyarakat Dalam Layanan Sosial Ekonomi Pemerintah Kabupaten Lampung Timur. Jurnal Ilmiah Administrasi Publik dan Pembangunan.Vol.2, No.5, Juli-Desember 2008

Juniarso Ridwan dan Achmad Sodik Sudrajat. 2010 Hukum Administrasi Negara dan Kebijakan Pelayanan Publik. Bandung: Penerbit Nuansa.

Hardiyansyah. 201I. Kualitas Pelayanan Publik. Yogyakarta : Gava Media

Mahmudi. 20I0. Manajemen Kinerja Sektor Publik, Edisi. kedua. Sekolah Tinggi Ilmu Manajemen YKPN. Yogyakarta.

Margono, S. 2003. Metode Penelitian Pendidikan. Jakarta: Rineka Cipta.

Pasolong, Harbani. 20II. Teori Administrasi Publik. Bandung: Alfabeta.

Ratminto \& Atik Septi Winarsih. 2007. Manajemen Pelayanan. Yogyakarta: Pustaka Pelajar

Sedarmayanti. 2010. Reformasi Administrasi Publik, Reformasi Birokrasi, dan Kepemimpinan Masa Depan (Mewujudkan Pelayanan Prima dan Kepemerintahan yang Baik). Bandung: PT Refika Aditama.

Sugiyono. 2013. Metode Penelitian Kuantitatif, Kualitatif, dan R\&D. Bandung: Alfabeta. 